Research Article

\title{
The Deformation Characteristics of Weak Foundation with High Back Siltation in the Immersed Tunnel
}

\author{
Xiabing Yue $\mathbb{D}$, Yuan Xie $\mathbb{D}$, and Yongli Xie \\ School of Highway, Chang'an University, Xi'an 710064, China \\ Correspondence should be addressed to Xiabing Yue; yuexb@chd.edu.cn and Yuan Xie; xieyuan@chd.edu.cn
}

Received 6 February 2018; Accepted 18 September 2018; Published 11 November 2018

Academic Editor: Raffaele Sepe

Copyright ( $\odot 2018$ Xiabing Yue et al. This is an open access article distributed under the Creative Commons Attribution License, which permits unrestricted use, distribution, and reproduction in any medium, provided the original work is properly cited.

\begin{abstract}
The deformation characteristics of a weak foundation with high back siltation in an immersed tunnel lack empirical data; however, the calculation method and control of foundation settlements are highly important to tunnel design and construction. This paper takes a cross section of the natural foundation of an immersed tunnel in the Hong Kong-Zhuhai-Macao Bridge (HZMB) as the research object and conducts a centrifuge model test. The soil layer is divided, and the soil parameters are determined by the CPTU and the indoor dynamic three triaxial test. In consideration of the actual engineering scale and the ability of the centrifuge model test system, the similarity ratio of the model to the prototype is studied and determined. As for the immersed tube structure, the deformation characteristics are mainly studied. Therefore, the organic glass is selected as the model material by the similarity of the elastic modulus and the density. The characteristics of the resilience and recompression of the natural foundation of the immersed tunnel and the strain characteristics of the immersed tube structure are obtained by the analysis of the multiworking condition test data. Moreover, based on the actual engineering geological conditions of the subsea tunnel, a numerical calculation method is carried out to check the reliability of the centrifuge model test results. The results of the numerical calculation are consistent with the model test results.
\end{abstract}

\section{Introduction}

An immersed tunnel is a large underwater tunnel that crosses rivers and straits. Since the completion of the first immersed tunnel in 1910 (the Detroit River immersed tunnel), immersed tunnels have developed rapidly throughout the world given their unique advantages [1-6]. When an underground building is constructed after unloading excavation, the additional load on the substrate is generally less than the initial overburden soil after construction; the settlement should therefore account for the specific stress loading path $[7,8]$. By comparing and analyzing settlement data from 19 immersed tunnels [9], results reveal that the average construction settlement period is $53 \mathrm{~mm}$, accounting for $55.9 \%$ of the total settlement. Uneven foundation settlement poses several hidden dangers to the immersed tunnel's structure, underscoring the importance of addressing settlement problems $[10,11]$.

Influenced by factors such as tunnel construction, tidal effects, riverbed siltation, and scour and declining regional groundwater level, vehicle periodic dynamic load, and earthquake load [12-20], immersed tunnels often exhibit uneven settlement. Accurate settlement analysis and control are crucial to the safety assessment of engineering structures and their smooth operation [21-25]. Over the past few decades, numerous research accomplishments have been realized in immersed tunnel settlement.

A large part of the tunnel is placed in a trench and is founded on soft marine clay. Therefore, it is very important to select the appropriate means of foundation reinforcement to restrict and control the settlement of the tunnel [26]. He et al. [27] reinforced the foundation of the immersed tunnel through the sand compaction pile. The results showed that the sand compaction pile (SCP) method had obvious settlement reduction effect on the marine clay. Foundation treatment of large sections of an immersed tunnel was optimized by Li et al. [28, 29] with positive effects. Ding et al. [30-32] exploited the three-dimensional numerical simulation methods to analyze the response law of the immersed tunnel under earthquake and analyzed in detail the weak 
links such as pipe joint of the immersed tunnel. Yoo [33] analyzed the influence of lining leakage on a subsea tunnel's structure and discovered that lining leakage increases the axial thrust and bending moment, with the latter being more obvious. Chen et al. [34,35] carried out an immersed tunnel shaking the table test. Results proved helpful in uncovering possible failure mechanisms in underwater immersed tunnels. Taking the immersed tunnel of HZMB (Hong KongZhuhai-Macao Bridge) as an example, $\mathrm{Hu}$ put forward a theoretical analysis method of the semirigid element segment based on the body-spring model [36]. However, due to the complex geological environment and substantial engineering and high technical difficulties, research on the HZMB (Hong Kong-Zhuhai-Macao Bridge) immersed tunnel's settlement analysis and control remains elusive; indeed, little research exists regarding various settlement problems.

The object of this study is the K9 + 600 section of the immersed tunnel of the HZMB (Hong Kong-Zhuhai-Macao Bridge). Application of a centrifugal model test to simulate the whole construction process (including excavating the foundation trench, laying a cushion, placing the immersed tunnel, and backfilling) under different cushion thickness conditions revealed the tunnel's basement stress distribution characteristics and the immersed tunnel structure's strain characteristics during the excavation and backfill process [37, 38]. Finite element calculations were used to verify the centrifuge test results and compensate for the lack of test data [39-42]. The foundation's stress distribution and deformation characteristics during construction are further revealed, providing a theoretical basis for engineering construction and the design of a foundation treatment plan [43].

\section{General Engineering Situation}

The main HZMB (Hong Kong-Zhuhai-Macao Bridge) project is a combined bridge and tunnel, in which the artificial islands and an immersed tunnel are key components. The total length of the subsea tunnel is about $6.7 \mathrm{~km}$, and the immersed tube method was adopted in the construction process. The immersed tunnel section extends from K6 +961 to $\mathrm{K} 12+751$; it is composed of 33 mega caisson tubes and the closing segment joint. The tunnel length from east to west is $90 m+90 m+180 \times 30 m+79 m$ (length is $5659 m$ ), making it the world's longest undersea tunnel. The tunnel's characteristics include a deeply dug trench; a long tube section; deep water depth; large silting load; soft, uneven foundation soil; complex immersed tunnel joint force; and construction difficulties. Geological sections and geographical locations are shown in Figures 1 and 2.

This paper's research object is the $\mathrm{K} 9+600$ section in the middle tunnel. The soil layer distribution from the top to the bottom is muck $(13.0 \mathrm{~m})$, silt clay $(6.8 \mathrm{~m})$, clay with sand $(9.7 \mathrm{~m})$, clay $(7.8 \mathrm{~m})$, medium sand $(5.7 \mathrm{~m})$, and coarse sand $(31.1 \mathrm{~m})$. The sea surface height is $-8.9 \mathrm{~m}$, and the trench excavation depth is $34.2 \mathrm{~m}$. The gravel mat gradation is good, the material size is moderate and does not contain sundries, the mud content is no greater than $3 \%$, and the maximum particle size is no greater than $31.5 \mathrm{~mm}$.

\section{Centrifuge Modelling}

The centrifuge model test can cause the model soil to exhibit stress and strain states similar to the prototype. Results of the test meet key similarity conditions; thus, centrifuge models have been widely applied in geotechnical engineering [4448]. Compared with the other test methods, advantages of the centrifuge model test include the following:

(1) This test is the most direct and effective means of structural design optimization, scheme comparison, and evaluation. For some complex engineering cases, finite element calculations cannot be conducted with existing physical quantities, and finite element calculation results cannot achieve the desired requirements. Currently, centrifugal model tests represent an essential empirical method.

(2) The test can be repeated several times on the same soil sample, saving considerable time, manpower, and material resources.

(3) Qualitative analysis of the centrifuge model test can enhance the main factors influencing test results, ignore minor factors, simplify test devices and equipment, and facilitate detailed study of all relevant factors.

This test used the TLJ-3 geotextile centrifuge from Chang'an University, which has a maximum capacity of $60 \mathrm{gt}$. In the experiment, geometric similarity was realized by a reduced scale, and gravity loss caused by the centrifugal inertia force compensation model was applied to ensure dynamic similarity. Using the concept of the proportional factor, the centrifugal force field's potential energy is converted to kinetic energy in an experiment exerting significant influence on the inertia process or gravity; the ratio factor is $1 / n$.

\subsection{Testing Material and Model Preparation. According to} the collection status of soil samples at the engineering stage, samples from the natural subgrade of the subsea tunnel were classified and collected. Soil engineering properties at the initial survey and a detailed survey of the project and piezocone penetration test (CPTU) results were used to prepare the corresponding test soil samples. The silt soil's weight in the model was determined by the maximum silting amount of the engineering design. Organic glass was selected as an analog material for the immersed tunnel and was processed into a tunnel model consistent with the prototype force. The model rate " $n$ " was 100 , and the corresponding centrifugal acceleration was $100 \mathrm{~g}$. According to the similarity theorem, to ensure the model floor's rigidity, the side wall and midpartition wall were equal to the prototype; $\mathrm{EI}=E \times$ $b h 3 / 12$ was used to determine thickness to ensure the stress acting on the base was consistent with the prototype. Model parameters are shown in Table 1. The size of the model box was $70 \mathrm{~cm}$ (length) $\times 40 \mathrm{~cm}$ (width) $\times 50 \mathrm{~cm}$ (height).

3.2. Data Acquisition and Measurement. Test data were mainly acquired through the experimental data acquisition 


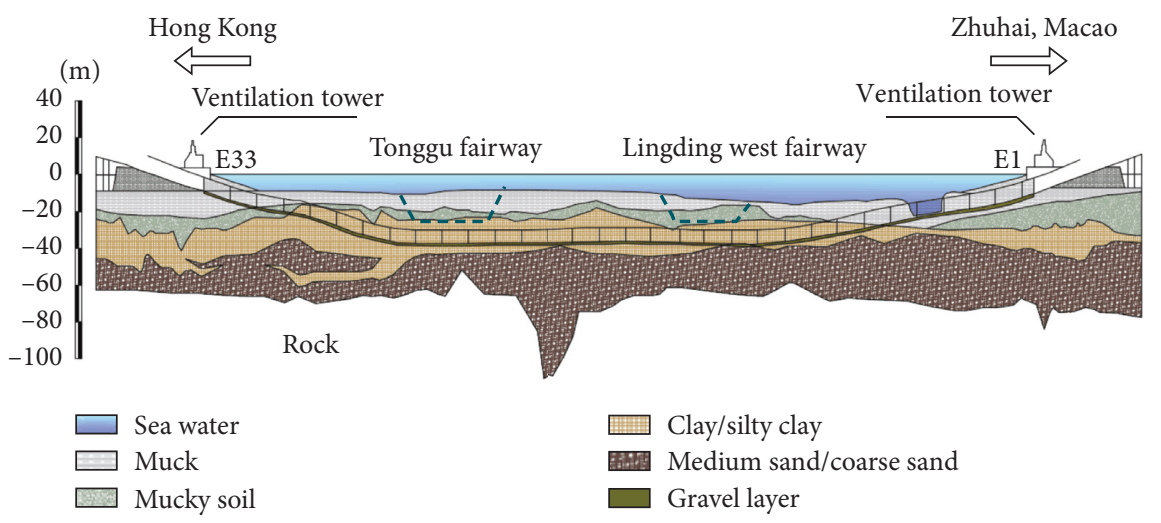

Figure 1: Geological section map.

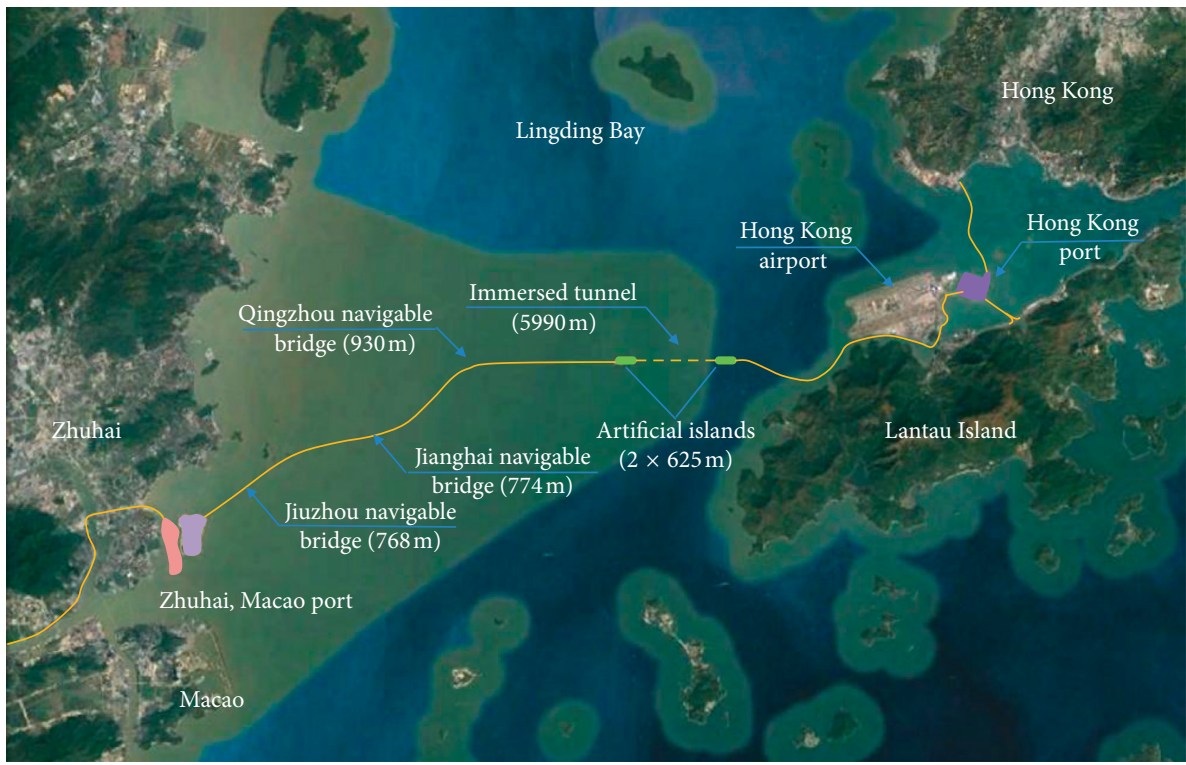

Figure 2: Geographic location diagram.

TABle 1: Model and prototype parameter comparison table.

\begin{tabular}{lcc}
\hline Item & Prototype & Model \\
\hline Elastic modulus $(\mathrm{MPa})$ & 30000 & 20000 \\
The thickness of side wall $(\mathrm{m})$ & 1.5 & 0.02329 \\
The thickness of bottom $(\mathrm{m})$ & 1.5 & 0.02329 \\
Thickness of middle partition wall $(\mathrm{m})$ & 0.8 & 0.0035 \\
Height $(\mathrm{m})$ & 11.44 & 0.126 \\
\hline
\end{tabular}

system. A microsoil pressure sensor, micropore water pressure sensor, strain gauge, and high-precision laser displacement sensor measured the original data, which were transmitted through the data acquisition system. This process reflected the system level and ability of the centrifugal model test; hence, such equipment is integral to the centrifugal measurement system.

A master-slave data acquisition system of $60 \mathrm{gt}$ centrifuge facilities was used in this experiment. The system is fast, accurate, and reliable. Its main feature breaks through traditional data transmission via the collector ring. Data acquisition is only completed through the front-end machine, and the digital signal of the EAI level is transmitted between the front end and the host. The front-end machine is composed of an industrial control machine, signal conditioning and amplification, A/D conversion, and digital communication. The core is an industrial control machine. The entire circuit was placed near the shielding box centrifuge so the front-end machine components could withstand the centrifugal force generated by the centrifuge's high-speed rotation. The mainframe uses a system microcomputer with an RS-232C communication interface to achieve system control, speed measurement, data processing, display, and printing. In the test, a highresolution closed-circuit television camera system was used to monitor the test process through real-time monitoring via the model box's organic glass, as shown in Figure 3.

In this test, corresponding measurement sensors were arranged based on the main test indices $[49,50]$, as shown in Figure 4(a).

S1-S6 show the earth pressure sensor along the transverse trench bottom layout; S7-S9 show the earth 


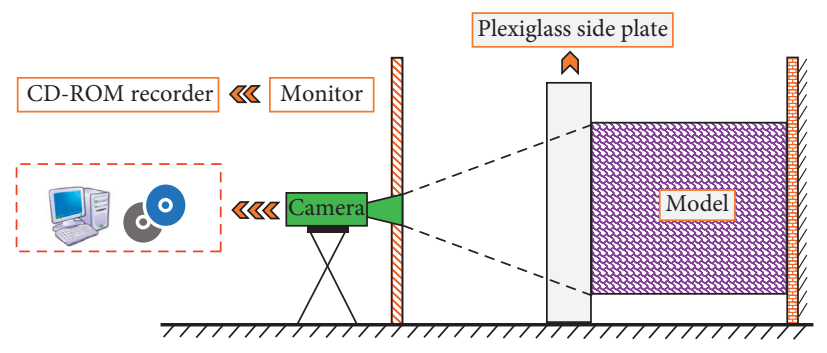

FIGURE 3: Monitoring system.

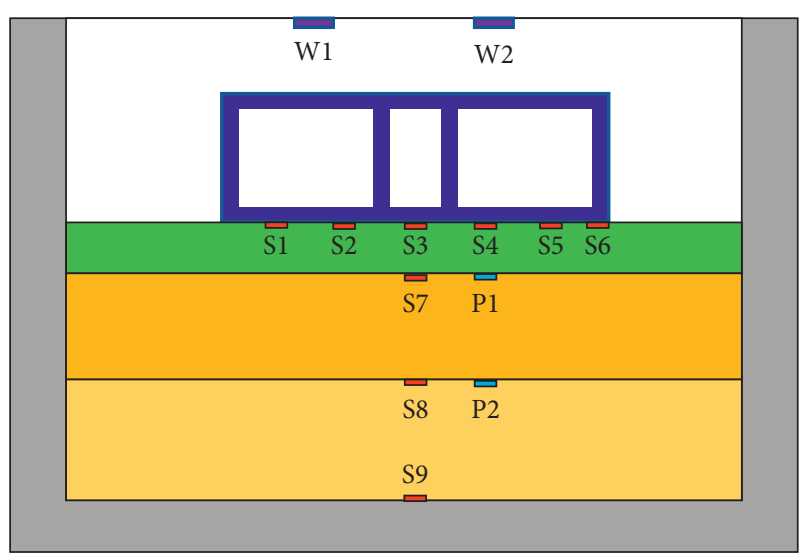

Earth pressure sensor

Laser displacement sensor

$\varpi$ Pore water pressure box sensor

(a)

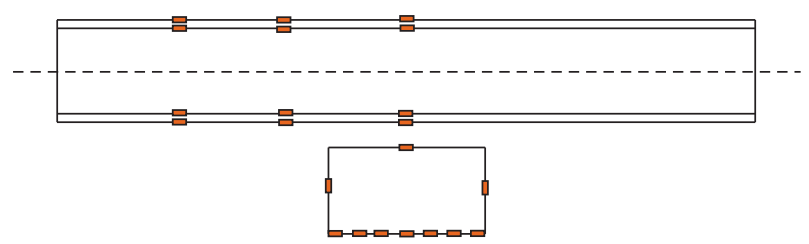

- High-sensitivity strain gauge

(b)

FIgURE 4: Test section and sensor arrangement: (a) layout of the pressure sensor; (b) layout of strain gauges.

pressure sensor set at different soil layer boundaries along the depth direction. P1 and P2 are pore water pressure box sensors, and W1 and W2 are laser displacement sensors. The high-sensitivity strain gauges, such as those displayed in Figure 4(b), were arranged on the bottom and each side of the immersed tunnel to measure immersed tunnel strain changes during the test. These tests were all conducted automatically using the DDS data acquisition system in the centrifuge test.

3.3. Experimental Research Contents. The standard working condition (cushion is $1.5 \mathrm{~m}$ ) and special working conditions (cushion layer thickness is $0 \mathrm{~m}, 1 \mathrm{~m}$, and $2 \mathrm{~m}$, respectively) were carried out in the centrifuge model test. Specific implementation conditions are shown in Table 2.
TABLE 2: Test scheme.

\begin{tabular}{lr}
\hline Test condition & Test index \\
\hline $\begin{array}{l}\text { Standard } \\
\text { working }\end{array}$ & $\begin{array}{r}\text { (1) Foundation stress; (2) foundation settlement; } \\
\text { (3) foundation rebound deformation; (4) } \\
\text { condition }\end{array}$ \\
$\begin{array}{r}\text { characteristics of pressure change at the bottom } \\
\text { of the cushion; (5) immersed tunnel strain }\end{array}$ \\
$\begin{array}{l}\text { Special working } \\
\text { condition }\end{array}$ & $\begin{array}{r}\text { (3) foundation stress; (2) foundation settlement; } \\
\text { immersed tunnel strain; (5) effect of cushion }\end{array}$ \\
\hline
\end{tabular}

Testing procedures are as follows:

(1) According to the distribution of soil properties in the section, the corresponding remolded soil samples were selected from the respective field samples. Water was added to the samples, and they were stirred sufficiently, so gas in the original soil was discharged to achieve ideal saturation, thereby creating the soil sample configuration needed for the test. Based on the centrifuge test model rate and actual soil layer distribution in the tested section, stratified fill soil was used to make the test conditions as similar as possible to the actual soil conditions. Before filling the soil, an adequate amount of silicone oil was applied to the model box's four walls to reduce the friction effect on the side wall and accelerate soil consolidation. Based on previous test results, soil preconsolidation time was determined at $100 \mathrm{~g}$ of centrifugal acceleration. The centrifuge was started with stratified fill soil to render the immersed tunnel and foundation soil models similar to the prototype state. According to the sampling standard of the original soil in geotechnical testing, the four undisturbed soil samples were removed from the centrifugal model at a certain depth in the box with a ring knife smeared with Vaseline. Direct shear tests were then conducted on the samples [51-54], and test and field results were compared to verify the degree of sample consolidation and the closest actual situation (Figure 5); this process determined the time required to complete the original consolidation speed and rotation.

(2) The actual excavation slope was large, and the size of the centrifuge model box was limited. The overlying soil layer could not be placed completely in the model box. According to similarity theory, the overlying soil can be converted to a high-density 


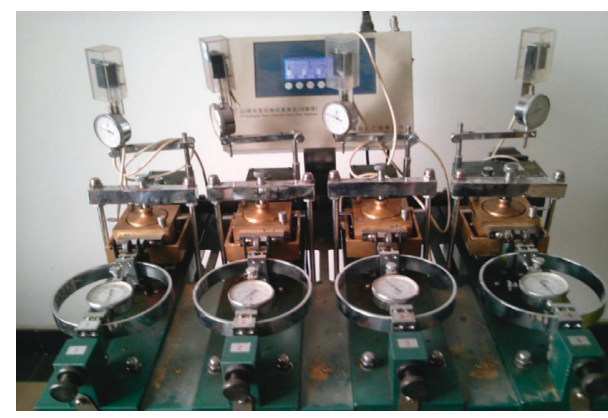

Figure 5: Direct shear test diagram.

weight block to satisfy the base stress. The created model was placed into the centrifuge's hanging basket, an earth pressure and pore water pressure sensors were connected, and the laser displacement sensors were installed.

(3) Construction stage simulation: when the initial consolidation was completed, the centrifuge was closed. The weight block was removed to simulate excavation and make the stress release and rebound when the foundation soil was unloading. After that, the gravel cushion was laid, the immersed tunnel model was placed, and the soil for backfill and silting was replaced by the weight block. After starting the machine, the load was graded according to the actual construction schedule [55]. When $t=15 \mathrm{~min}$ (about $104 \mathrm{~d}$ in the field), the centrifugal acceleration reached $100 \mathrm{~g}$ equivalent to the actual state of the prototype after backfilling. Then, at a stable speed of $100 \mathrm{~g}$, the centrifuge continued to run for $156 \mathrm{~min}$ to simulate the foundation soil layer operation in the 3 years after backfilling.

(4) Data from each measurement system in the test process were extracted and processed. All test steps are shown in Figure 6.

3.4. Interpretation of Test Results. According to the similarity law, the model test data results were converted into corresponding prototype values, and the results were compared and analyzed with the numerical calculation (a negative value indicates a compression state).

3.4.1. Stress Variety Process of Foundation. Figure 7 depicts the distribution curve of the stress values measured by different earth pressure sensors within 3 years of backfilling. When the centrifuge reached the set speed and turned steadily, the stress value first increased slightly over time, and then the curve became gentle. The rebound soil after excavation was gradually compacted and extruded under a sustained and steady load, and during the rebound process, the pore water absorbed by the soil drained away gradually. Analysis of the experimental data revealed that the pore water pressure increased with time as the centrifugal speed increased. After the speed stabilized, the pore water pressure showed no growth trend and slowly dissipated.
3.4.2. Displacement of Foundation. The laser displacement sensor measured the corresponding displacement value of the foundation after each construction phase. After excavation, the rebound displacement was $4.07 \mathrm{~cm}$, and the recompression amount was $5.12 \mathrm{~cm}$ after backfilling. Because the excavation depth of this section was comparatively large, after backfilling, the load of the upper part of the foundation was large and the recompression amount exceeded the rebound.

3.4.3. Effect of Cushion. Figure 8 depicts the stress distribution curve of the base under different cushion thickness conditions. All curves were saddle shaped. The value of the base stress in the driveway, the midpartition wall, and the side walls of the immersed tunnel increased in turn. By comparing the distribution curve of basal stress under different cushion thickness conditions, the curve amplitude was highest without a cushion. At this time, the base stress value of the immersed tunnel's side wall and midpartition wall was largest, and the base stress value of the driveway corresponded to the minimum. As cushion thickness increased, the stress distribution curve of the base became gentle. Cushion thickness therefore appears to exert a great influence on the foundation's working characteristics. When the cushion was thinner, the amplitude of the basal stress distribution curve was bigger, and the stress concentration phenomenon was more obvious. Moreover, the immersed tunnel's stress value at the side wall and the midpartition wall increased as cushion thickness decreased. The cushion therefore served to level the foundation. Under load, the cushion layer did not exert much stress concentration through lateral extrusion deformation. The cushion placement increased the base's vertical reverse force and created a homogenization effect on the basal stress.

Figure 9 illustrates the stress distribution curve of the base center point along the foundation depth under different cushion thickness conditions after backfilling. The stress value increased in line with depth. The thicker the cushion, the smaller the stress value at the same depth, but the difference between the stresses gradually became smaller as depth increased. That is, the thinner the cushion, the more obvious the stress concentration of the midpartition wall corresponding to the base part and the greater the stress transferred to the foundation; this effect was found to decrease with depth.

Figure 10 presents a diagram of the strain distribution curve of the immersed tunnel bottom plate under different cushion thickness conditions. After the centrifuge reached a steady speed, the strain curves of the immersed tunnel model were all saddle shaped, and the bottom part of the tunnel's side walls and midpartition wall showed an upper side pull; the driveway part showed a lower side pull.

By comparing the strain curves corresponding to different cushion thickness conditions, it is clear that the amplitude of the immersed tunnel's strain distribution curve was largest when the cushion thickness was $0 \mathrm{~m}$, and the strain produced at this time was obviously greater than when the cushion was placed.

Due to the special structure of the immersed tunnel, stress generated by the water pressure and backfill load was 


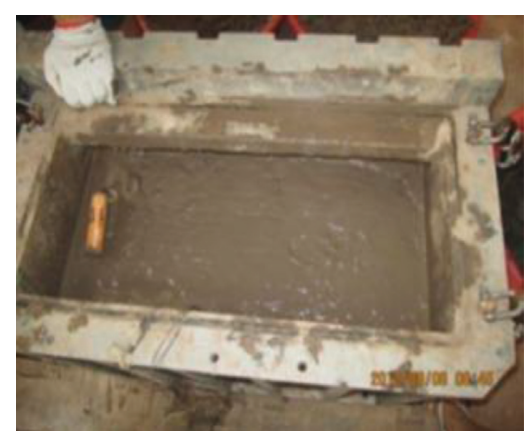

(a)

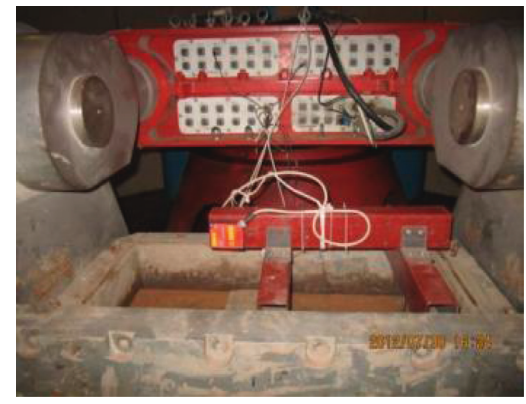

(d)

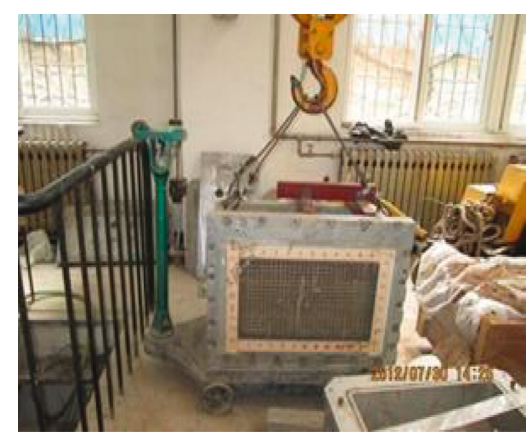

(b)

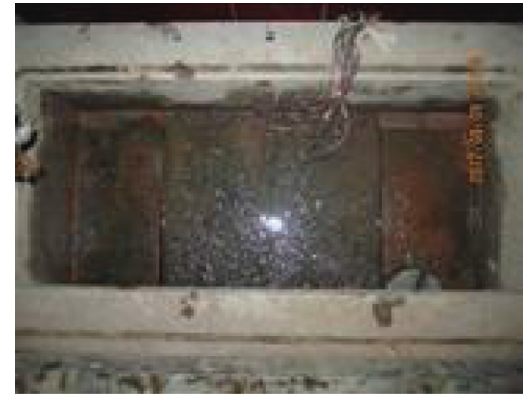

(e)

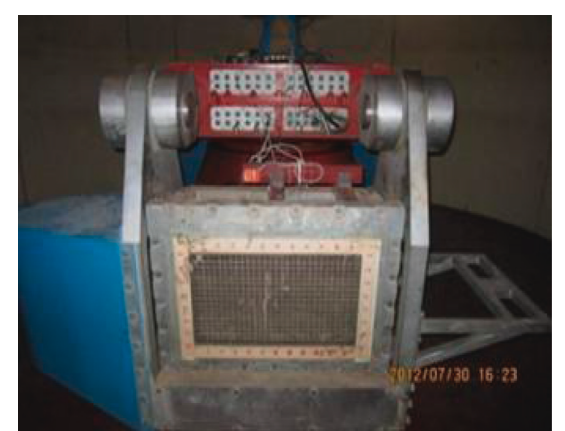

(c)

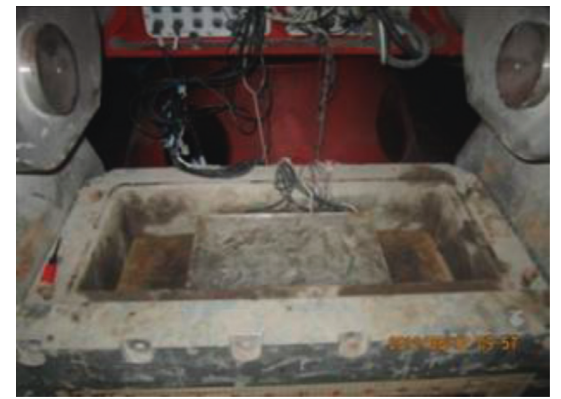

(f)

FIgURE 6: Test process: (a) fill in the soil sample; (b) hoisting the model box; (c) immobilization; (d) initial consolidation; (e) paving cushion; (f) placement of the immersed tunnel.

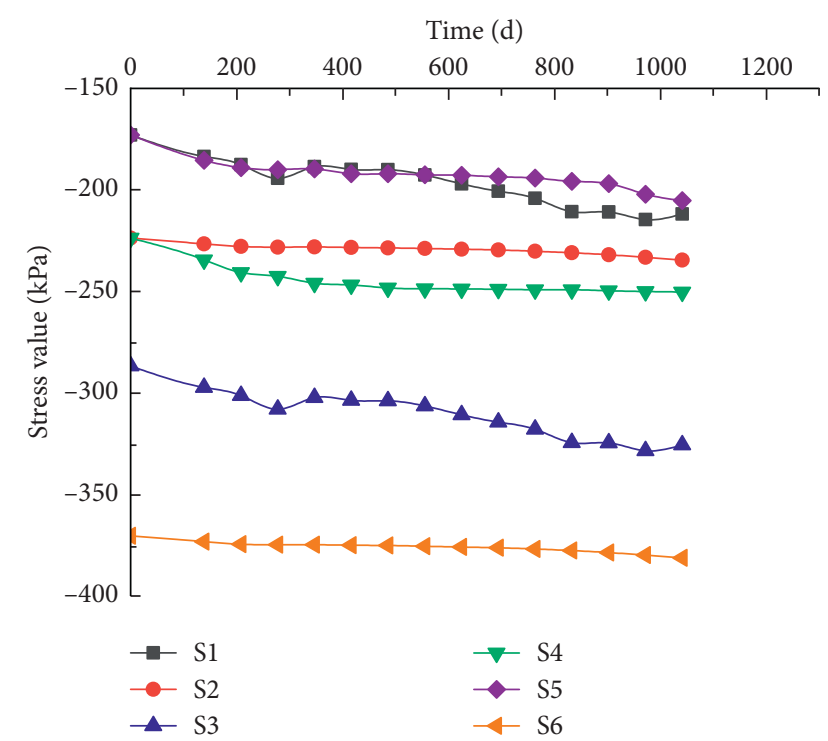

Figure 7: Stress-time distribution curve.

transferred from the side wall and the midpartition wall to the foundation, and the immersed tunnel produced some strain. When the immersed tunnel was placed on the cushion, the cushion played a role in coordinating the tunnel's deformation (and that of the cushion itself) through inner particle movement. When the cushion was thicker, the strain curve was gently distributed, and the strain of the bottom plate was smaller. Therefore, ensuring appropriate cushion thickness is essential to reducing and coordinating the immersed tunnel deformation.

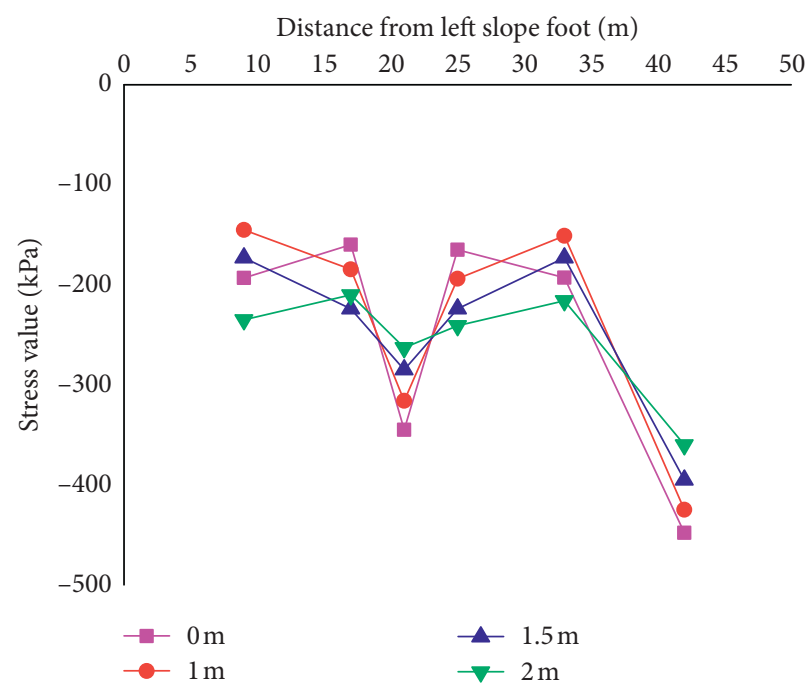

Figure 8: Distribution curve of base stress.

Table 3 presents the base displacement of different working conditions measured by a laser displacement sensor. Figure 11 depicts the foundation settlement change curve under different cushion thickness conditions 3 years after backfilling. The basal subsidence in the 3 years after completion increased over time before finally becoming stable. Different cushion thickness conditions corresponded to different recompressing displacements. When the cushion thickness was $2 \mathrm{~m}$, the amount of recompression reached the minimum; thus, the cushion appeared to exert a controlling effect on settlement in the construction process. But after 3 


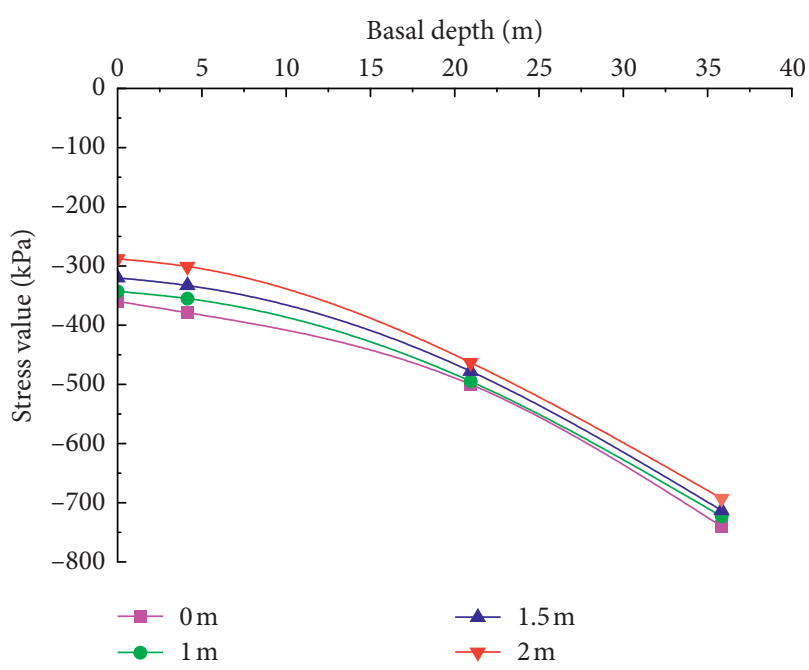

FIgURE 9: The vertical stress curve of the axis of the base.

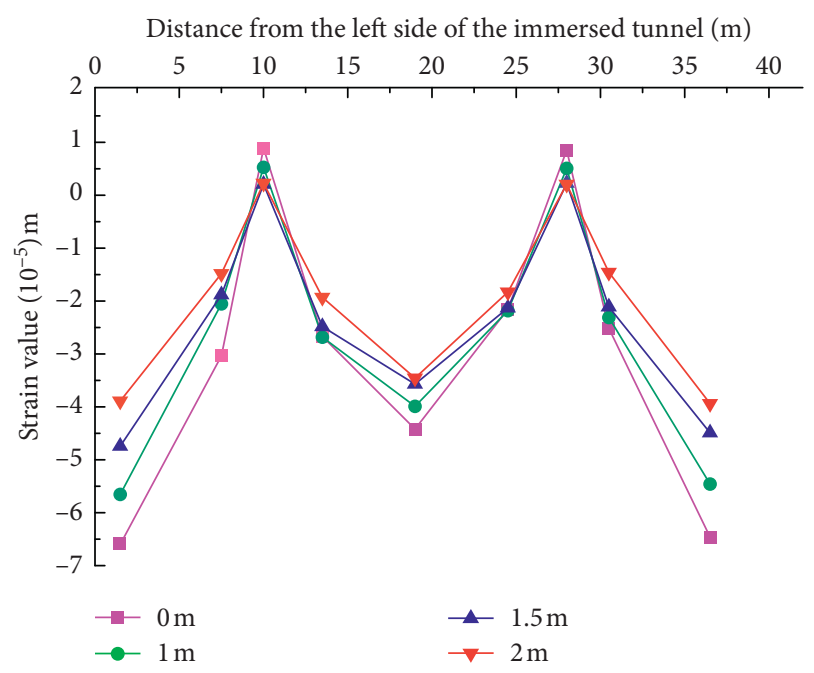

FIgURE 10: Strain distribution curve of the immersed tunnel bottom plate.

TABLE 3: Settlement under different working conditions.

\begin{tabular}{lcc}
\hline $\begin{array}{l}\text { Thickness of } \\
\text { cushion }(\mathrm{m})\end{array}$ & $\begin{array}{c}\text { Recompression } \\
\text { displacement }(\mathrm{cm})\end{array}$ & $\begin{array}{c}\text { Settlement within } \\
\text { three years }(\mathrm{cm})\end{array}$ \\
\hline 0 & 5.89 & 3.21 \\
1 & 5.61 & 2.36 \\
1.5 & 5.12 & 2.04 \\
2 & 4.47 & 2.49 \\
\hline
\end{tabular}

years, the settlement was not still at the minimum. When the cushion thickness was $1.5 \mathrm{~m}$, the settlement was smallest. Therefore, cushion thickness and postconstruction settlement showed no obvious linear relationship, and reasonable cushion thickness could reduce subsidence. In summary, the base displacement was reduced as cushion thickness increased. Considering factors such as cushion thickness and immersed tunnel stiffness, it is necessary to determine reasonable cushion thickness, which will play a productive role in controlling engineering building settlement.

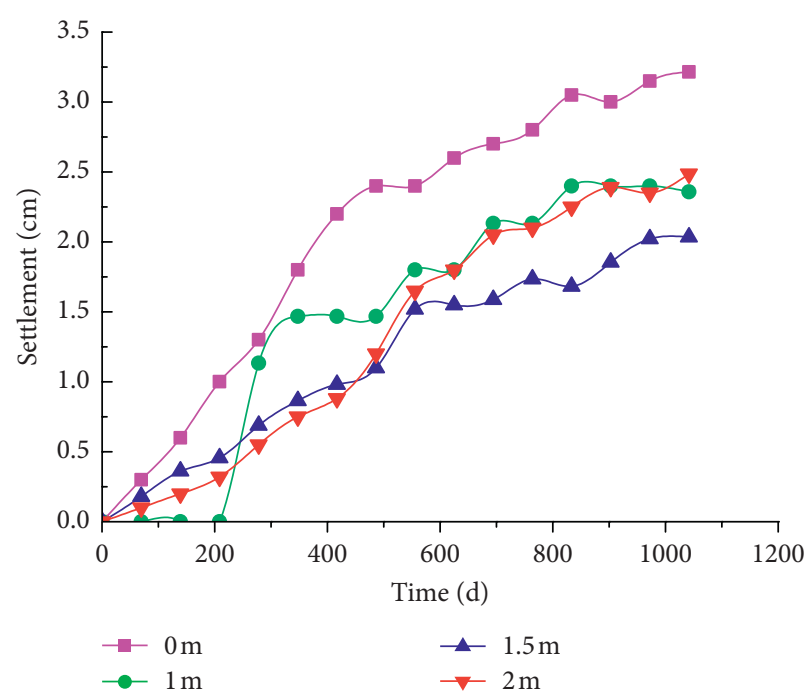

FIGURE 11: Settlement curve after completion of construction.

When the immersed tunnel model was removed at the end of the test, the cushion change differed: the thickness was $1 \mathrm{~m}$, and when the immersed tunnel was removed, some clay mud infiltrated the cushion material and made the bottom uneven. When the cushion thickness was $2 \mathrm{~m}$, the cushion showed better integrity after removing the immersed tunnel. That is, the cushion adjusted to basal stress and displacement, creating different stress distributions and cushion thickness displacements.

Overall, the effects of the cushion were as follows:

(1) The cushion layer played a homogenizing role in the immersed tunnel's foundation, and the cushion thickness greatly influenced the foundation's working characteristics [56]. The thinner the cushion layer, the greater the amplitude of the basal stress distribution curve, and the more obvious the stress concentration phenomenon. The stress values of the two sides and the middle wall of the immersed tunnel increased as cushion thickness decreased.

(2) Under backfill and silting load, the cushion was compressed through lateral deformation; hence, the deformation of the immersed tunnel and cushion and the cushion and foundation can be coordinated, the immersed tunnel strain should decline, and the foundation's stress distribution should homogenize.

(3) After construction, the immersed tunnel models' strain curves were all saddle shaped. The cushion placement can reduce the strain values on each point of the immersed tunnel's bottom plate and reduce the strain distribution curve's amplitude.

(4) The cushion placement reduced uneven settlement and decreases postconstruction settlement. However, the effect of an overly thick cushion on settlement was not clear; therefore, reasonable cushion thickness can reduce excessive stress concentration in the immersed tunnel structure and exerts a controlling effect on the foundation settlement. 


\section{Finite Element Analysis}

Due to the limited number of earth pressure sensors and laser displacement sensors, the centrifugal test can only get the data of the test points and cannot reflect the deformation of the foundation and the distribution curves of the base displacement. Therefore, based on the conditionality and shortcomings of the centrifuge model test, ADINA software was used to establish the finite element model. The model includes foundation trench excavation, cushion placement, immersed tunnel installation, and backfill of the entire construction process to complement and verify the centrifuge model test results.

4.1. Model Parameters. From the centrifuge model test and CPTU (the piezocone penetration test) results, reliable calculation parameters are provided for the numerical calculation model [57] (Table 4). Related rock and soil mechanics parameters were selected from the design data as calculation parameters of the immersed tunnel and backfill soil, as shown in Table 5.

4.2. Boundary Conditions. The horizontal displacement constraints are applied to the left and right boundaries of the model; the strong weathered granite is at the bottom, and the vertical displacement constraint is applied at the bottom boundary.

Because the stress at all levels is accumulated on the basis of the initial stress, it has an influence on the calculation of initial loading and the calculation of the subsequent loads at all levels, the stress state of the initial loading should be determined before the subsequent calculation. However, the initial stress state of the real soil is difficult to be calculated accurately. As an approximate estimate, the self-weight stress field of soil can be regarded as its initial stress field.

4.3. Model Establishment. In the model, the foundation soil is based on the Mohr-Coulomb criterion, and the elastic model is selected for backfill, cushion materials, and immersed tunnel. Because the corresponding materials in different soil layers, immersed pipes, backfill soil, and the cushion were different, the whole model was divided into nine different element groups during model development. Thus, each element group corresponds to one material. The model's initial soil layer coincides with parts of the immersed tunnel, cushion, backfilling, and silting. These grids are defined as different unit groups and materials. Then, the birth and death element was applied to simulate the actual construction process. In the consolidation stage, only the original soil layer units were activated, and the other units were "killed". At the time of excavation, the soil is layered "killed," and in the backfilling stage, the cushion, immersed tube, and backfill are sequentially activated. To avoid nonconvergence of the model calculation and ensure uniform mesh generation, the model divided the lines first and then the faces before finally manually adjusting the local area's shape and density. The width of the model is $320 \mathrm{~m}$, the height is $64 \mathrm{~m}$, and the immersed tube size is identical with the prototype (height is $11.4 \mathrm{~m}$, and width is $37.95 \mathrm{~m}$ ). The number of nodes is 7612, and the number of elements is 7630. The grid partition is shown in Figure 12.

4.4. Rebound Deformation Characteristics. Figure 13 shows the resilience displacement cloud map after excavation. The vertical displacement of the bottom soil layer after excavation was positive, and the whole soil layer was rebound $[58,59]$. But in the section on both sides of the interface, a recompression phenomenon appeared because the trench excavation unloading reduced additional stress on the excavation surface to zero. The soil on both sides was squeezed into the middle due to gravity stress $[60,61]$. In addition, as the foundation depth increased, this effect gradually weakened. With the maximum rebound in the trench surface and as the depth increased, displacement distribution was generally stable and the rebound decreased gradually until its depth reached zero.

Figure 14 depicts the distribution curve of rebound displacement after excavation. The curve of the basal rebound arched after excavation. The minimum rebound displacement was at both ends of the edge slope excavation face; the peak was at the center. The maximum difference of rebound was about $3 \%$.

Figure 15 is the distribution curve of the rebound displacement along the depth. From the diagram, the axis is consistent with the excavation slope foundation below the rebound distribution curve along the ground depth trend. The difference between the two rebound amounts is smaller than the total rebound. The foundation rebound mainly occurred in a range below the excavation surface; as the foundation depth increased, the rebound decreased gradually and the curve slowed. Because the soil layer of this section was evenly distributed, the two curves retained a parallel distribution with a small difference.

4.5. Recompression Deformation Characteristics. The recompression of the substrate after backfilling is shown in Figure 16. The vertical displacement of the original excavation face was negative, indicating soil recompression deformation. The maximum amount of recompression appeared in the trench surface. As the soil depth deepened, recompression decreased gradually.

The maximum compression of the base occurred at $6.5 \mathrm{~cm}$, and the average recompression was approximately $6 \mathrm{~cm}$, as shown in Figure 17. The recompression curve was saddle shaped. The side wall, midpartition wall, and driveway corresponding the basal recompression of the immersed tunnel decreased in turn due to the immersed tunnel's structural characteristics and the drop-down action of the two sides of backfill soil on the tunnel's side wall.

The axis and excavation slope foundation below the compression volume along the soil depth distribution trend curves were essentially the same, as shown in Figure 18. As the foundation depth increased, the recompression decreased gradually. Recompression reached $66 \%$ of the total compression in the depth extent of 0.5 times the width of the 
TABLE 4: Soil layer parameters.

\begin{tabular}{lccccccc}
\hline Soil & $\begin{array}{c}\text { Poisson's } \\
\text { ratio }\end{array}$ & $\begin{array}{c}\text { Cohesive } \\
\text { force }(\mathrm{kPa})\end{array}$ & $\begin{array}{c}\text { Internal friction } \\
\text { angle }\left(^{\circ}\right)\end{array}$ & $\begin{array}{c}\text { Buoyant density } \\
\left(\mathrm{kg} \cdot \mathrm{m}^{-3}\right)\end{array}$ & $\begin{array}{c}\text { Compression } \\
\text { modulus (MPa) }\end{array}$ & $\begin{array}{c}\text { Resilient } \\
\text { modulus }(\mathrm{MPa})\end{array}$ & $\begin{array}{c}\text { Recompression } \\
\mathrm{modulus}(\mathrm{MPa})\end{array}$ \\
\hline Silt & 0.430 & 7.2 & 19.9 & 680 & - & - & - \\
Clay & 0.400 & 60 & 28.8 & 760 & 24 & - & - \\
Silty clay & 0.400 & 54 & 30.0 & 840 & 23.69 & 159.96 & 145.69 \\
Clay grit & 0.296 & 50 & 18.5 & 870 & 25.54 & 198.77 \\
Medium sand & 0.296 & 20 & 37.8 & 1030 & 34.26 & 87.73 \\
Coarse sand & 0.290 & 18 & 38.3 & 1100 & 40.8 & 236.6 & 80.76 \\
\hline
\end{tabular}

TABLE 5: Calculation parameters.

\begin{tabular}{lccc}
\hline Material & Poisson's ratio & Deformation modulus $(\mathrm{MPa})$ & ${\text { Buoyant density }\left(\mathrm{kg} \cdot \mathrm{m}^{-3}\right)}$ \\
Backfill soil & 0.37 & 150 & 1000 \\
Broken stone cushion & 0.45 & 20 & 900 \\
Immersed tunnel & 0.2 & 30000 & - \\
\hline
\end{tabular}

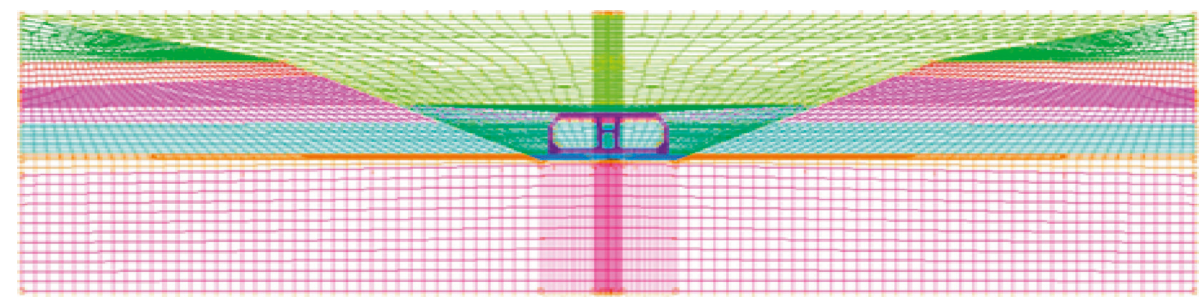

FIGURE 12: Grid partition schematic diagram.

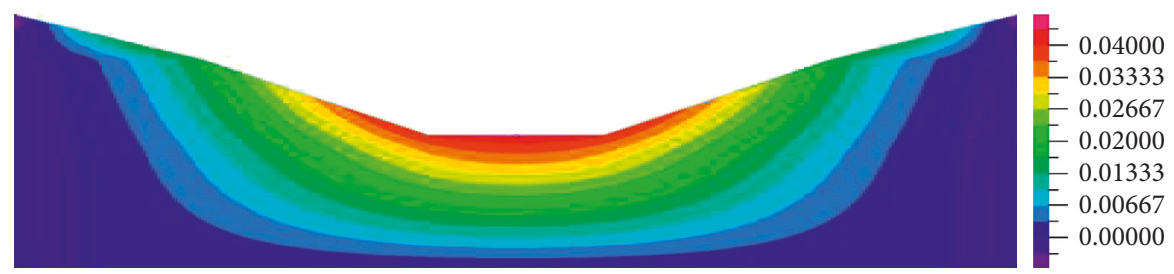

FIgURE 13: Displacement cloud map after excavation (unit: m).

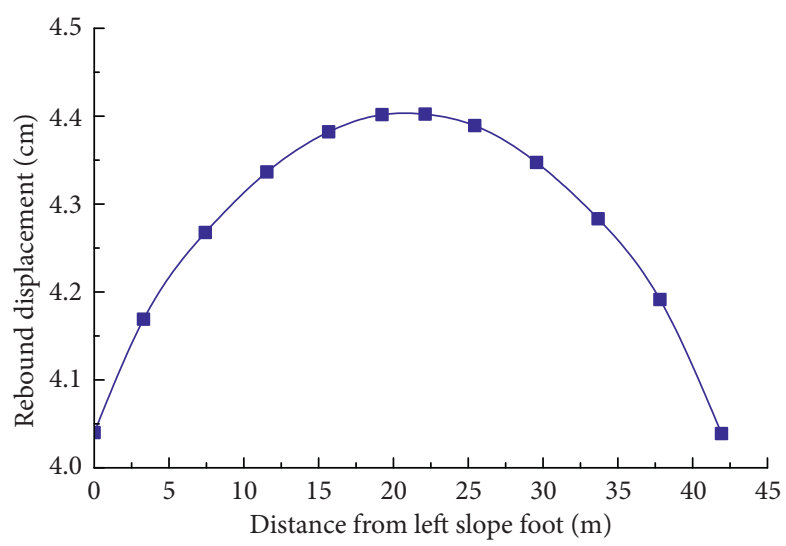

Figure 14: Rebound displacement of trench bottom. 


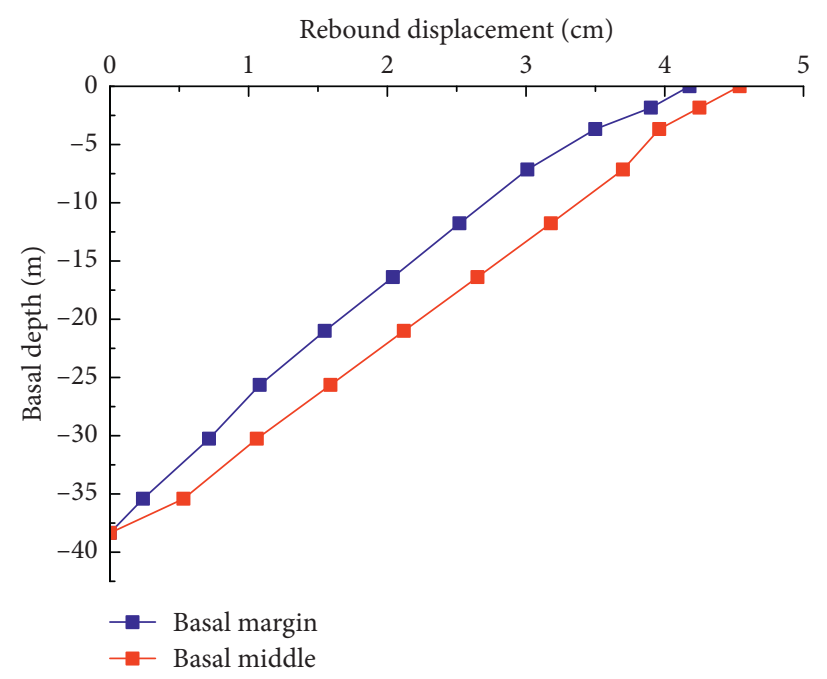

Figure 15: Rebound displacement along the depth distribution.

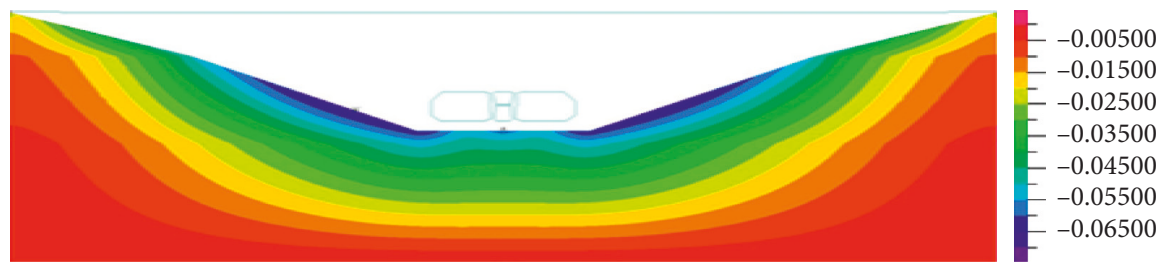

FIgURE 16: Displacement cloud map after backfill (unit: m).

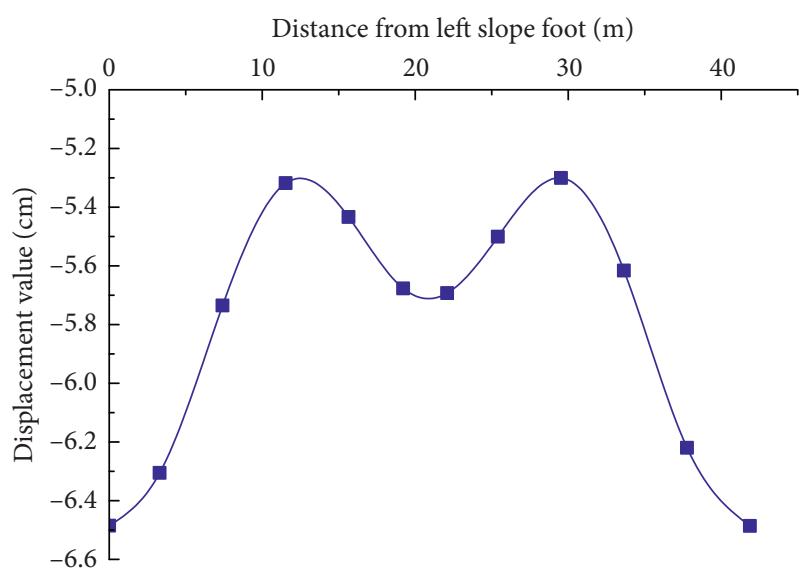

FIGURE 17: Recompression displacement diagram after backfilling.

foundation trench. At a depth of $4 \mathrm{~m}$ below the base, there was an obvious turning point in the curve: the cohesive soil was more compressible, and the consolidation process slowed. However, the sand layer's consolidation time was brief, so the compression change rate was smaller than that of clay.

\section{Comparison and Verification}

5.1. Basal Stress. Figure 19 shows the vertical stress distribution curve of the foundation along the middle axis under standard working conditions after backfilling. The

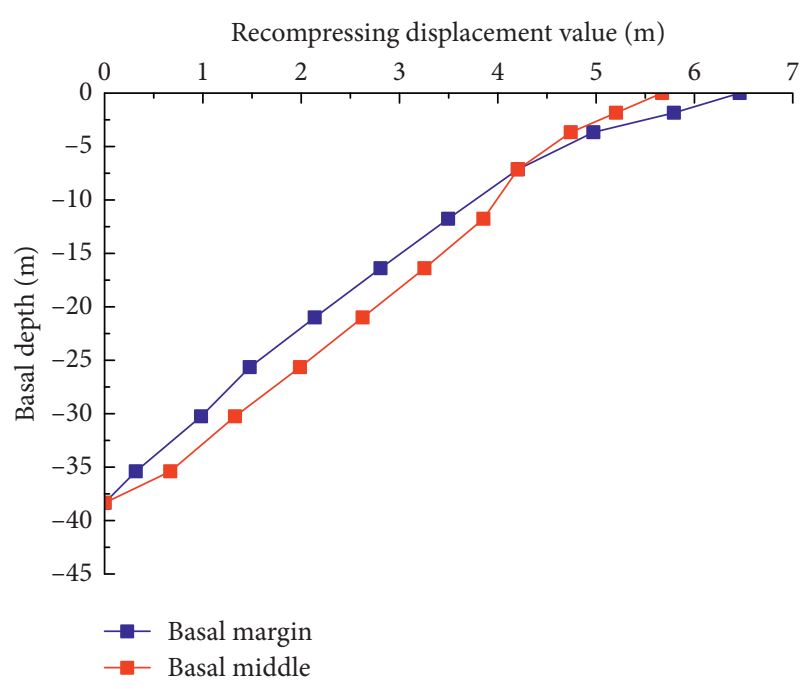

Figure 18: Recompression displacement along the depth distribution.

experimental curve agreed well with the numerical calculation curve. With increasing foundation depth, the stress value of the center point in the direction of the base also increased. Due to the small density of clay, the growth rate of corresponding stress with depth was relatively slow, and the curve was gentle. When entering the sand layer, the density increased, stress increased in line with depth, and the curve 


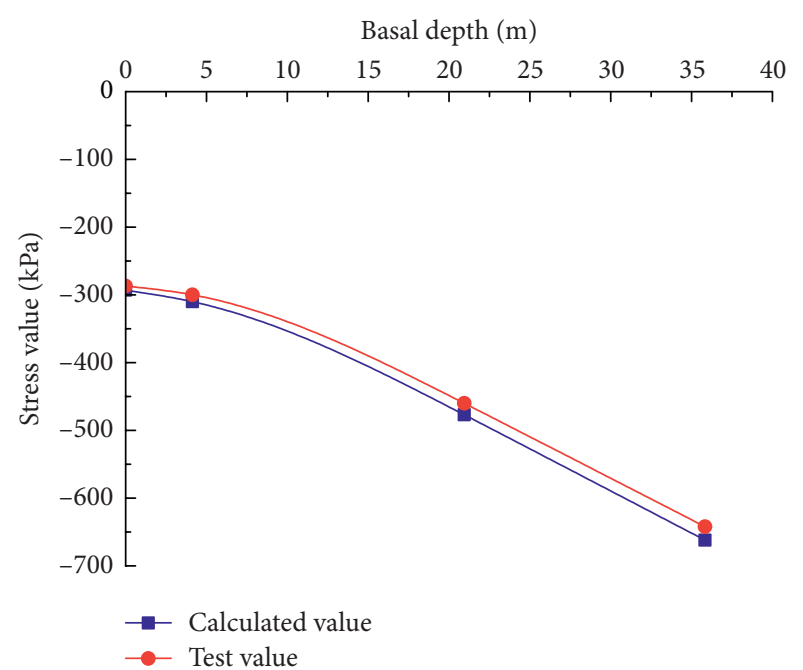

Figure 19: The vertical stress curve of the axis of the base.

became steeper; therefore, an obvious turning point existed in the stress curve at the boundary between clay and sand.

The trench bottom surface along the transverse stress distribution curve under the standard working conditions after backfilling is shown in Figure 20 [62, 63]. The test curve again concurred with the numerical results. After the completion of the backfill, the trench bottom along the horizontal direction of the stress distribution exhibited a saddle shape. The side wall, midpartition wall, and driveway corresponding to the immersed tunnel's basal stress value decreased sequentially.

5.2. Immersed Tunnel Strain. The strain change in the immersed tunnel structure after backfilling plays an important role in the design of the immersed tunnel and foundation treatment scheme. Figure 21 shows the vertical strain curve distribution map of various points on the immersed tunnel floor in the centrifuge model test after construction. The curve of the numerical calculation results was similar to that of the centrifugal model test, and the overall test value was smaller than the calculated value. After construction, the vertical strain curve of the bottom plate was saddle shaped under water pressure and soil pressure. The strain value of the immersed tunnel lane was positive, and the strain direction was upward (i.e., a tensile state). However, the strain value of the immersed tunnel's side wall and the midpartition wall was negative (i.e., a compression state). From a numerical perspective, the strain was not large, suggesting that a properly thick cushion may be laid to increase the base's stiffness and reduce deformation.

5.3. Deformation of Foundation. Based on the comparative analysis of the centrifuge model tests and numerical simulation results under standard conditions, the distribution of stress and strain and the immersed tunnel's strain characteristics were very similar to those of the numerical simulation. The results of basilar strain contrast, as shown in Table 6 , and the difference percentages were $6.0 \%$ and $4.30 \%$,

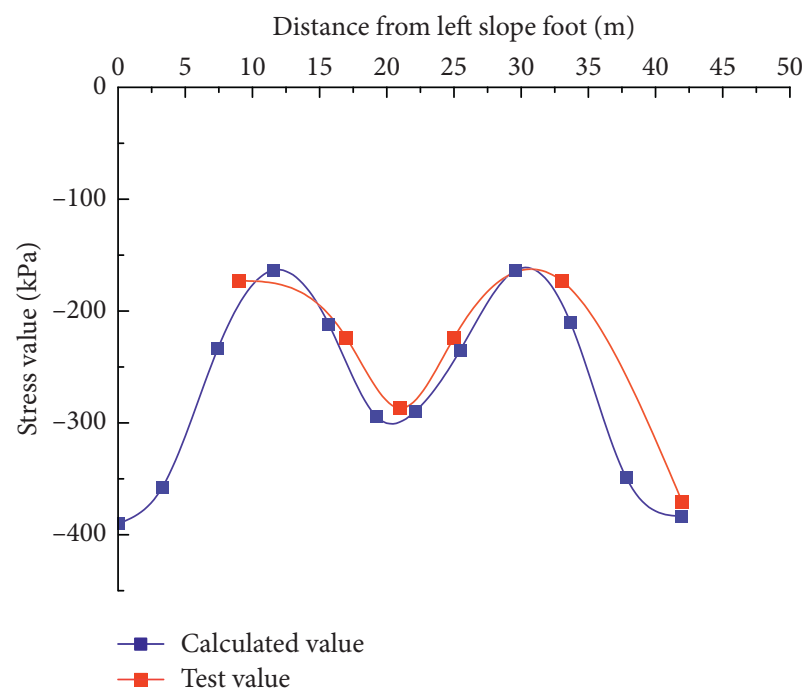

Figure 20: Transverse stress distribution curve of base.

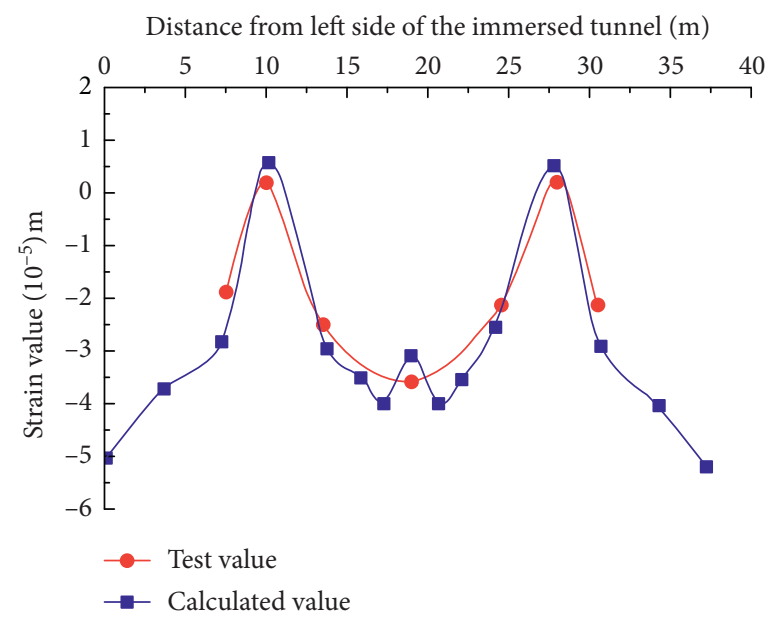

FIGURE 21: Immersed tunnel strain curve.

TABle 6: Comparison of results.

\begin{tabular}{lcc}
\hline & $\begin{array}{c}\text { Rebound } \\
\text { displacement }(\mathrm{cm})\end{array}$ & $\begin{array}{c}\text { Recompression } \\
\text { displacement }(\mathrm{cm})\end{array}$ \\
\hline $\begin{array}{l}\text { Numerical simulation } \\
\text { results }\end{array}$ & 4.33 & 5.35 \\
$\begin{array}{l}\text { Centrifuge model } \\
\text { test results }\end{array}$ & 4.07 & 5.12 \\
\hline
\end{tabular}

respectively. In conclusion, these two settlement calculations are reliable and rational, providing a simple calculation method for predicting settlement deformation [64-70].

\section{Consideration of Lateral Uneven Settlement}

The immersed tunnel's side wall and midpartition wall were influenced by force transmission, so the foundation stress was bigger, making the foundation settlement larger than the lane. However, from the centrifugal 
model test and numerical simulation calculation, the settlement difference of the immersed tunnel section was not great; the settlement difference was less than $4 \mathrm{~mm}$, smaller than the reserved deformation at the immersed tunnel's joint. Therefore, it is not necessary to consider special treatment for it.

\section{Conclusions}

This paper used a centrifugal model test and finite element analysis to simulate the construction process of the HZMB's (Hong Kong-Zhuhai-Macao Bridge) K9 + 600 section of an immersed tunnel with a weak foundation. The stress and strain characteristics of the excavated backfill base and the deformation characteristics of the immersed tunnel structure were studied, providing some basis for engineering design [71-77]. The concrete results are as follows:

(1) After backfilling and siltation, the stress distribution in the base was saddle shaped. The side wall, midpartition wall, and driveway corresponding to the basal stress value of the immersed tunnel decreased sequentially, and the maximum difference of stress is near $200 \mathrm{kPa}$.

Within 3 years of construction, the stress increased with time and tends to be steady, and the maximum increment was about $40 \mathrm{kPa}$.

(2) The vertical strain curve of the immersed tunnel model was saddle shaped. The bottom of the immersed tunnel's side wall and midpartition wall belonged to an upper drawing state, while the section of the driveway belonged to a lower drawing state. After the immersed tunnel strain stabilized, the change of its corresponding variable over time remained mostly the same. The cushion placement reduced the strain value of each point in the bottom of the immersed tunnel, so the tunnel's strain curve distribution was gentle.

(3) The cushion layer played a homogenizing role in the immersed tunnel's foundation, and the cushion thickness had a great influence on the foundation's working properties. The thinner the cushion, the greater the amplitude of the basal stress distribution curve, and the more significant the stress concentration phenomenon.

(4) After excavation, the foundation's rebound deformation is arched. After backfilling and silting, the recompression deformation was saddle shaped, and the rebound and recompression deformation decrease as depth increased. Due to the compaction settlement of the backfilled lithotripsy on both sides of the immersed tunnel, downward tensile stress was produced on the tunnel's side wall, so the recompression of the base's center point base was obviously smaller than that at the edge. The deformation difference along the transverse direction decreased gradually with depth and eventually disappeared. After construction, the base's recompression deformation was about 1.2 times than that of the rebound deformation.

\section{Data Availability}

The data used to support the findings of this study are available from the corresponding author upon request.

\section{Conflicts of Interest}

The authors declare that there are no conflicts of interests regarding the publication of this paper.

\section{Acknowledgments}

This work was financially supported by the National Science and Technology Support Program (No. 2011BAG07B00) and National Key R\&D Program of China (No. 2017YFC0805306).

\section{References}

[1] N. S. Rasmussen, "Concrete immersed tunnels-forty years of experience," Tunnelling and Underground Space Technology, vol. 12, no. 1, pp. 33-46, 1997.

[2] A. Glerum, "Developments in immersed tunnelling in Holland," Tunnelling and Underground Space Technology, vol. 10, no. 4, pp. 455-462, 1995.

[3] N. S. Rasmussen, "Immersed tunnels," Structural Engineering International, vol. 5, no. 4, p. 213, 1995.

[4] M. Morris, M. W. W. Yang, C. K. Tsang, A. Y. M. Hu, and D. S. C. Shut, "An overview of subsea tunnel engineering in Hong Kong," Proceedings of the Institution of Civil EngineersCivil Engineering, vol. 169, no. 6, pp. 9-15, 2016.

[5] L. C. F. Ingerslev, "Considerations and strategies behind the design and construction requirements of the Istanbul Strait immersed tunnel," Tunnelling and Underground Space Technology, vol. 20, no. 6, pp. 604-608, 2005.

[6] O. Kiyomiya, "Earthquake-resistant design features of immersed tunnels in Japan," Tunnelling and Underground Space Technology, vol. 10, no. 4, pp. 463-475, 1995.

[7] B. Schmidt and W. C. Grantz, "Settlements of immersed tunnels," Journal of Geotechnical and Geoenvironmental Engineering, vol. 105, no. 9, pp. 1031-1047, 1979.

[8] W. C. Grantz, "Immersed tunnel settlements," Tunnelling and Underground Space Technology, vol. 16, no. 3, pp. 203-210, 2001.

[9] G. Wei, H.-J. Qiu, and X.-J. Wei, “Analysis of construction and poet-construction settlement data caused by immersed tunnel," Chinese Journal of Rock Mechanics and Engineering, vol. 32, pp. 3413-3420, 2013.

[10] P.-X. Shi, D.-L. Zhang, J.-L. Pan, and W. Liu, "Geological investigation and tunnel excavation aspects of the weakness zones of Xiang'an subsea tunnels in China," Rock Mechanics and Rock Engineering, vol. 49, no. 12, pp. 4853-4867, 2016.

[11] J.-L. Qiu, H.-Q. Liu, J.-X. Lai et al., "Investigating the long term settlement of a tunnel built over improved loessial foundation soil using jet grouting technique," Journal of Performance of Constructed Facilities, vol. 32, no. 5, article 04018066, 2018. 
[12] T. Kasper, J. S. Steenfelt, L. M. Pedersen, P. G. Jackson, and R. W. M. G. Heijmans, "Stability of animmersed tunnel in offshore conditions under deep water wave impact," Coastal Engineering, vol. 55, no. 9, pp. 753-760, 2008.

[13] A. Gokce, F. Koyama, M. Tsuchiya, and T. Gencoglu, "The challenges involved in concrete works of Marmaray immersed tunnel with service life beyond 100 years," Tunnelling and Underground Space Technology, vol. 24, no. 5, pp. 592-601, 2009.

[14] G.-C. Yang, X.-H. Wang, X.-G. Wang et al., "Analyses of seepage problems in a subsea tunnel considering effects of grouting and lining structure," Marine Georesources and Geotechnology, vol. 34, no. 1, pp. 65-70, 2014.

[15] Q. Zhang, S. Draper, L. Cheng, and H. An, "Effect of limited sediment supply on sedimentation and the onset of tunnel scour below subsea pipelines," Coastal Engineering, vol. 116, pp. 103-117, 2016.

[16] X.-X. Nie, X.-B. Wei, X.-C. Li, and C. Lu, "Heat treatment and ventilation optimization in a deep mine," Advances in Civil Engineering, vol. 2018, Article ID 1529490, 12 pages, 2018.

[17] Q.-X. Yan, H. Chen, W.-Y. Chen, J. Zhang, S. Ma, and $\mathrm{X}$. Huang, "Dynamic characteristic and fatigue accumulative damage of a cross shield tunnel structure under vibration load," Shock and Vibration, vol. 2018, Article ID 9525680, 14 pages, 2018.

[18] J.-X. Lai, K.-Y. Wang, J.-L. Qiu, F. Niu, J. Wang, and J. Chen, "Vibration response characteristics of the cross tunnel structure," Shock and Vibration, vol. 2016, Article ID 9524206, 16 pages, 2016.

[19] Z. Wang, Y. Xie, H. Liu et al., "Analysis on deformation and structural safety of a novel concrete-filled steel tube support system in loess tunnel," European Journal of Environmental and Civil Engineering, 2018.

[20] Z.-F. Wang, Y.-Q. Wang, and W.-C. Cheng, "Investigation into geohazards during urbanization process of Xi'an, China," Natural Hazards, vol. 92, no. 3, pp. 1937-1953, 2018.

[21] J.-L. Qiu, X.-L. Wang, J.-X. Lai et al., "Response characteristics and preventions for seismic subsidence of loess in Northwest China," Natural Hazards, vol. 92, no. 3, pp. 1909-1935, 2018.

[22] J.-X. Lai, S.-Y. He, J.-L. Qiu et al., "Characteristics of seismic disasters and aseismic measures of tunnels in Wenchuan earthquake," Environmental Earth Sciences, vol. 76, no. 2, 2017.

[23] Y. C. Zheng, K. Liu, Y. Fang et al., "Rockburst prediction model based on entropy weight integrated with grey relational-BP neural network," Advances in Civil Engineering, 2018.

[24] P.-F. Li, F. Wang, and Q. Fang, "Undrained analysis of ground reaction curves for deep tunnels in saturated ground considering the effect of ground reinforcement," Tunnelling and Underground Space Technology, vol. 71, pp. 579-590, 2018.

[25] S. He, L. Su, H. Fan, and R. Ren, "Methane explosion accidents of tunnels in SW China," Geomatics, Natural Hazards and Risk, 2018, In press.

[26] T. Kasper, J. S. Steenfelt, L. M. Pedersen, P. G. Jackson, and R. W. M. G. Heijmans, "Stability of an immersed tunnel in offshore conditions under deep water wave impact," Coastal Engineering, vol. 55, no. 9, pp. 753-760, 2008.

[27] H. He, Y. Lin, J. Li, and N. Zhang, "Immersed tunnel foundation on marine clay improved by sand compaction piles," Marine Georesources and Geotechnology, vol. 36, no. 2, pp. 218-226, 2017.

[28] Y.-D. Li, J. Cui, H.-H. Mo, W. Li, and J. Yuan, "Sand deposit arrangement and construction optimization for large-section immersed tube tunnel foundations via the sand flow method,"
Soil Mechanics and Foundation Engineering, vol. 54, no. 5, pp. 324-329, 2017.

[29] W. Li, Y. Fang, and H. Mo, "Model test of immersed tube tunnel foundation treated by sand-flow method," Tunnelling and Underground Space Technology, vol. 40, no. 2, pp. 102108, 2014

[30] J.-H. Ding, X.-L. Jin, Y.-Z. Guo, and G.-G. Li, "Numerical simulation for large-scale seismic response analysis of immersed tunnel," Engineering Structures, vol. 28, no. 10, pp. 1367-1377, 2006.

[31] I. Anastasopoulos, N. Gerolymos, V. Drosos, R. Kourkoulis, T. Georgarakos, and G. Gazetas, "Nonlinear response of deep immersed tunnel to strong seismic shaking," Journal of Geotechnical and Geoenvironmental Engineering, vol. 133, no. 9, pp. 1067-1090, 2007.

[32] I. Anastasopoulos, N. Gerolymos, V. Drosos et al., "Behaviour of deep immersed tunnel under combined normal fault rupture deformation and subsequent seismic shaking," Bulletin of Earthquake Engineering, vol. 6, no. 2, pp. 213-239, 2008.

[33] C. Yoo, "Effect of water leakage in tunnel lining on structural performance of lining in subsea tunnels," Marine Georesources and Geotechnology, vol. 35, no. 3, pp. 305-317, 2017.

[34] H.-J. Chen, X.-J. Li, and W.-M. Yan, "Shaking table test of immersed tunnel considering the geological condition," Engineering Geology, vol. 227, pp. 93-107, 2017.

[35] X.-J. Cheng, L.-P. Jing, J. Cui et al., "Shaking-table tests for immersed tunnels at different sites," Advances in Materials Science and Engineering, vol. 2017, Article ID 2546318, 11 pages, 2017.

[36] Z.-N. Hu, Y.-L. Xie, G.-P. Xu et al., “Advantages and potential challenges of applying semi-rigid elements in an immersed tunnel: a case study of the Hong Kong-Zhuhai-Macao Bridge," Tunnelling and Underground SpaceTechnology, vol. 79, pp. 143-149, 2018.

[37] Q. Yan, Y. Xu, W. Zhang et al., "Numerical analysis of the cracking and failure behaviors of segmental lining structure of an underwater shield tunnel subjected to a derailed highspeed train impact," Tunnelling and Underground Space Technology, vol. 72, pp. 41-54, 2018.

[38] X.-B. Yue, Y.-L. Xie, H.-G. Zhang et al., "Centrifugal model experiment and numerical simulation of foundation rebound and recompression characteristic," Journal of Highway and Transportation Research and Development, vol. 31, no. 3, pp. 106-111, 2014.

[39] Q.-X. Yan, L.-Y. Song, H. Chen, W.-Y. Chen, S.-Q. Ma, and W.-B. Yang, "Dynamic response of segment lining of overlapped shield tunnels under train-induced vibration loads," Arabian Journal for Science and Engineering, vol. 43, no. 10, pp. 5439-5455, 2018.

[40] Q. Yan, W. Zhang, C. Zhang, and H. Chen, "Back analysis of water and earth loads on shield tunnel and structure ultimate limit state assessment: a case study," Arabian Journal for Science and Engineering, 2018.

[41] J.-X. Lai, S. Mao, J.-L. Qiu et al., "Investigation progresses and applications of fractional derivative model in geotechnical engineering," Mathematical Problems in Engineering, vol. 2016, Article ID 9183296, 15 pages, 2016.

[42] X.-L. Luo, L.-Y. Niu, and S.-G. Zhang, "An algorithm for traffic flow prediction based on improved SARIMA and GA," KSCE Journal of Civil Engineering, 2018.

[43] S.-G. Song, S.-C. Li, L.-P. Li et al., "Study on longitudinal deformation profile of rock, mass in a subsea tunnel," Marine Georesources and Geotechnology, vol. 34, no. 4, pp. 376-383, 2016. 
[44] J.-G. Qian, Q.-W. Wang, J.-H. Jiang, Y. Cai, and M. Huang, "Centrifuge modeling of a saturated clay ground under cyclic loading," International Journal of Geomechanics, vol. 18, no. 6, pp. 1-10, 2018.

[45] Z.-D. Cui and Y.-Q. Tang, "Land subsidence and pore structure of soils caused by the high-rise building group through centrifuge model test," Engineering Geology, vol. 113, no. 1-4, pp. 44-52, 2010.

[46] Z. N. Hu, Y. L. Xie, and J. Wang, "Challenges and strategies involved in designing and constructing a $6 \mathrm{~km}$ immersed tunnel: a case study of the Hong Kong-Zhuhai-Macao bridge," Tunnelling and Underground Space Technology, vol. 50, pp. 171-177, 2015.

[47] Y. W. Zhang, Z. P. Song, X. L. Weng, and Y. L. Xie, "A new soil-water characteristic curve model for unsaturated loess based on wetting-induced pore deformation," Geofluids, 2018.

[48] Y. Xie, C. F. Leung, and Y. K. Chow, "Centrifuge modelling of spudcan-pile interaction in soft clay overlying sand," Geotechnique, vol. 67, no. 1, pp. 69-77, 2016.

[49] J. Lai, X. Wang, J. Qiu et al., "Extreme deformation characteristics and countermeasures for a tunnel in difficult grounds in southern Shaanxi, China," Environmental Earth Sciences, vol. 77, no. 706, 2018.

[50] J.-X. Lai, J.-L. Qiu, H.-B. Fan et al., "Fiber bragg grating sensors-based in-situ monitoring and safety assessment of loess tunnel," Journal of Sensors, vol. 16, pp. 1-10, 2016.

[51] Y. Li, Y. Yang, H. Yu, and G. Roberts, "Principal stress rotation under bidirectional simple shear loadings," KSCE Journal of Civil Engineering, vol. 22, no. 5, pp. 1651-1660, 2018.

[52] Y. C. Zheng, S. S. Xu, H. Y. Liu et al., "Study on the influence partitions of proximity tunneling based on nonlinear multivariate regression," Advances in Civil Engineering, 2018.

[53] R. Ren, H. Zhou, Z. Hu et al., "Statistical analysis of fire accidents in Chinese highway tunnels 2000-2016," Tunnelling and Underground Space Technology, 2018, In press.

[54] R. Ren, D. Yu, L. Wang et al., "Typhoon triggered operation tunnel debris flow disaster in coastal areas of SE China," Geomatics, Natural Hazards and Risk, 2018.

[55] X.-B. Yue, "Research on settlement characteristics and calculation of immersed tube tunnel with soft foundation and high siltation," Ph.D. thesis, Chang'an University, Xi'an, China, 2013.

[56] J.-X. Lai, H.-Q. Liu, J.-L. Qiu et al., "Settlement analysis of saturated tailings dam treated by CFG pile composite foundation," Advances in Materials Science and Engineering, vol. 2016, Article ID 7383762, 10 pages, 2016.

[57] Z.-Q. Zhang, X.-Q. Shi, B. Wang, and H. Li, "Stability of NATM tunnel faces in soft surrounding rocks," Computers and Geotechnics, vol. 96, pp. 90-102, 2018.

[58] Z. N. Hu, Y. L. Xie, G. P. Xu et al., "Segmental joint model tests of immersed tunnel on a settlement platform: A case study of the Hongkong-Zhuhai-Macao Bridge," Tunnelling and Underground Space Technology, vol. 78, pp. 188-200, 2018.

[59] Z. Wang, Z. Hu, J. Lai et al., "Settlement characteristics of jacked box tunneling underneath a highway embankment," Journal of Performance of Constructed Facilities, 2018.

[60] J.-L. Qiu, X.-L. Wang, S.-Y. He, H. Liu, J. Lai, and L. Wang, "The catastrophic landside in Maoxian county, Sichuan, SW China, on June 24, 2017," Natural Hazards, vol. 89, no. 3, pp. 1485-1493, 2017.

[61] R. Ren, S.-S. Xu, Z.-D. Ren et al., "Numerical investigation of particle concentration distribution characteristics in twin- tunnel complementary ventilation system," Mathematical Problems in Engineering, pp. 1-13, 2018.

[62] X. Luo, D. Li, and S. Zhang, "Traffic flow prediction in holidays based on DFT and SVR," Journal of Sensors, 2018.

[63] Y. Li, S. Xu, H. Liu, E. Ma, and L. Wang, "Displacement and stress characteristics of tunnel foundation in collapsible loess ground reinforced by jet grouting columns," Advances in Civil Engineering, pp. 1-16, 2018.

[64] J.-X. Lai, J.-L. Qiu, Z.-H. Feng, J. Chen, and H. Fan, "Prediction of soil deformation in tunnelling using artificial neural networks," Computational Intelligence and Neuroscience, vol. 2016, Article ID 6708183, 16 pages, 2016.

[65] W. C. Grantz, "Immersed tunnel settlements. Part 1: nature of settlements," Tunnelling and Underground Space Technology, vol. 16, no. 3, pp. 195-201, 2001.

[66] J.-L. Qiu, Y.-W. Qin, J.-X. Lai, K. Wang, and F.-Y. Niu, "Structural response of the metro tunnel under local dynamic water environment in loess strata," Geofluids, 2018, in press.

[67] Z.-F. Wang, S.-L. Shen, and W.-C. Cheng, "Simple method to predict ground displacements caused by installing horizontal jet-grouting columns," Mathematical Problems in Engineering, vol. 2018, Article ID 1897394, 11 pages, 2018.

[68] J.-B. Wang, Z.-P. Song, B.-Y. Zhao, X. Liu, J. Liu, and J. Lai, “A study on the mechanical behavior and statistical damage constitutive model of sandstone," Arabian Journal for Science and Engineering, vol. 43, no. 10, pp. 5179-5192.

[69] C. Liu, Z. Fan, X. Chen et al., "Experimental study on bond behavior between section steel and RAC under full replacement ratio," KSCE Journal of Civil Engineering, 2018, In press.

[70] C. Liu, Z. Lv, C. Zhu et al., "Study on calculation method of long term deformation of RAC beam based on creep adjustment coefficient," KSCE Journal of Civil Engineering, 2018, In press.

[71] H.-J. Zhang, Z.-Z. Wang, F. Lu, G. Y. Xu, and W. G. Qiu, "Analysis of the displacement increment induced by removing temporary linings and corresponding countermeasures," Tunnelling and Underground Space Technology, vol. 73, pp. 236-243, 2018.

[72] L. Q. Cao, Q. Fang, D. L. Zhang, and T. L. Chen, "Subway station construction using combined shield and shallow tunnelling method: Case study of Gaojiayuan station in Beijing," Tunnelling and Underground Space Technology, 2018.

[73] W.-H. Zhou, H.-Y. Qin, J.-L. Qiu et al., "Building information modelling review with potential applications in tunnel engineering of China," Royal Society Open Science, vol. 4, no. 8, article 170174, 2017.

[74] J.-X. Lai, J.-L. Qiu, H.-B. Fan, J. Chen, and Y. Xie, "Freezeproof method and test verification of a cold region tunnel employing electric heat tracing," Tunnelling and Underground Space Technology, vol. 60, pp. 56-65, 2016.

[75] Z. J. Zhou, J. T. Lei, S. B. Shi et al., "Seismic response of Aeolian sand high embankment slopes in shaking table tests," Shock and vibration, 2018.

[76] H.-T. Yu, Y. Yuan, G.-P. Xu, Q. Su, X. Yan, and C. Li, "Multipoint shaking table test for long tunnels subjected to nonuniform seismic loadings-part II: application to the HZM immersed tunnel," Soil Dynamics and Earthquake Engineering, vol. 108, pp. 187-195, 2018.

[77] H.-T. Yu, X. Yan, A. Bobet, Y. Yuan, G. Xu, and Q. Su, "Multipoint shaking table test of a long tunnel subjected to nonuniform seismic loadings," Bulletin of Earthquake Engineering, vol. 16, no. 2, pp. 1041-1059, 2018. 


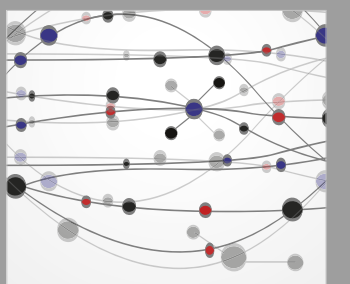

The Scientific World Journal
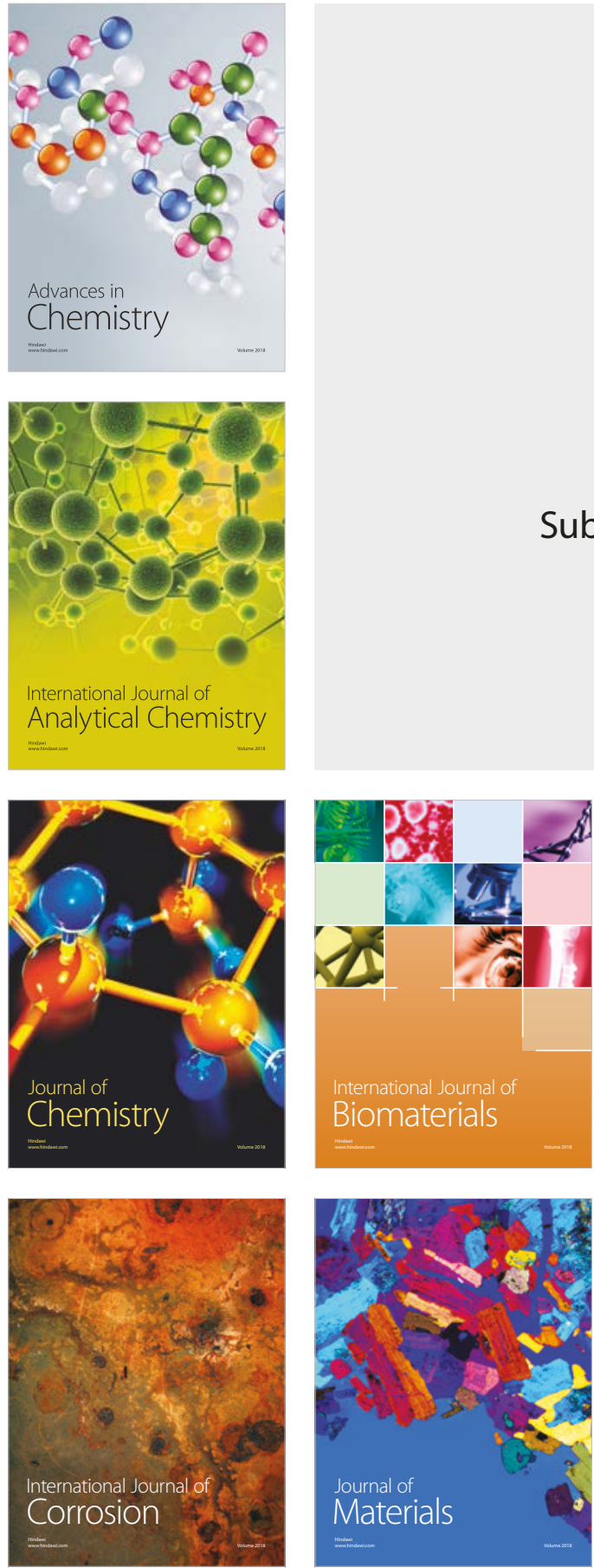

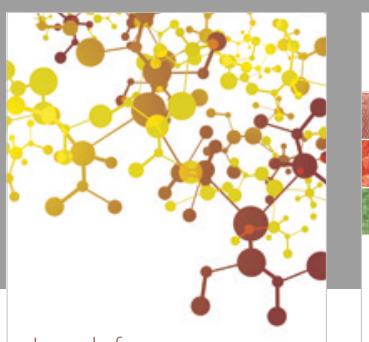

Journal of

Applied Chemistry
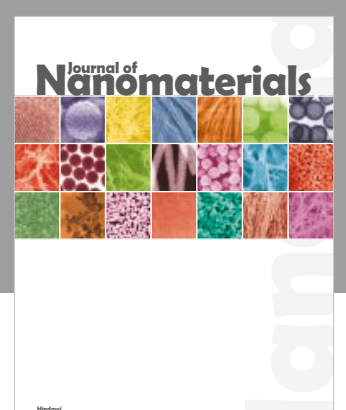

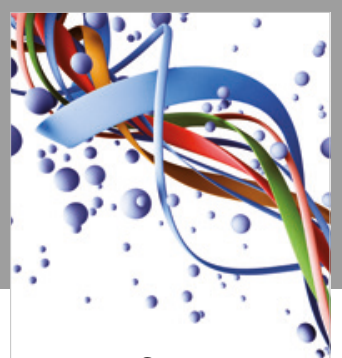

Scientifica

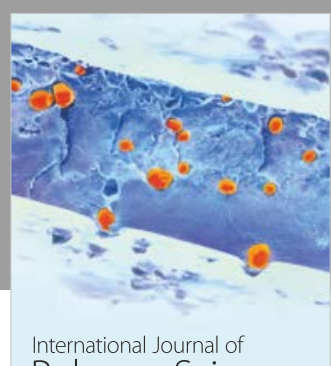

Polymer Science

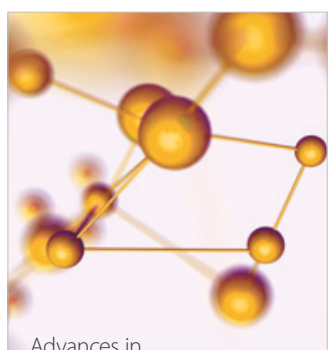

Physical Chemistry
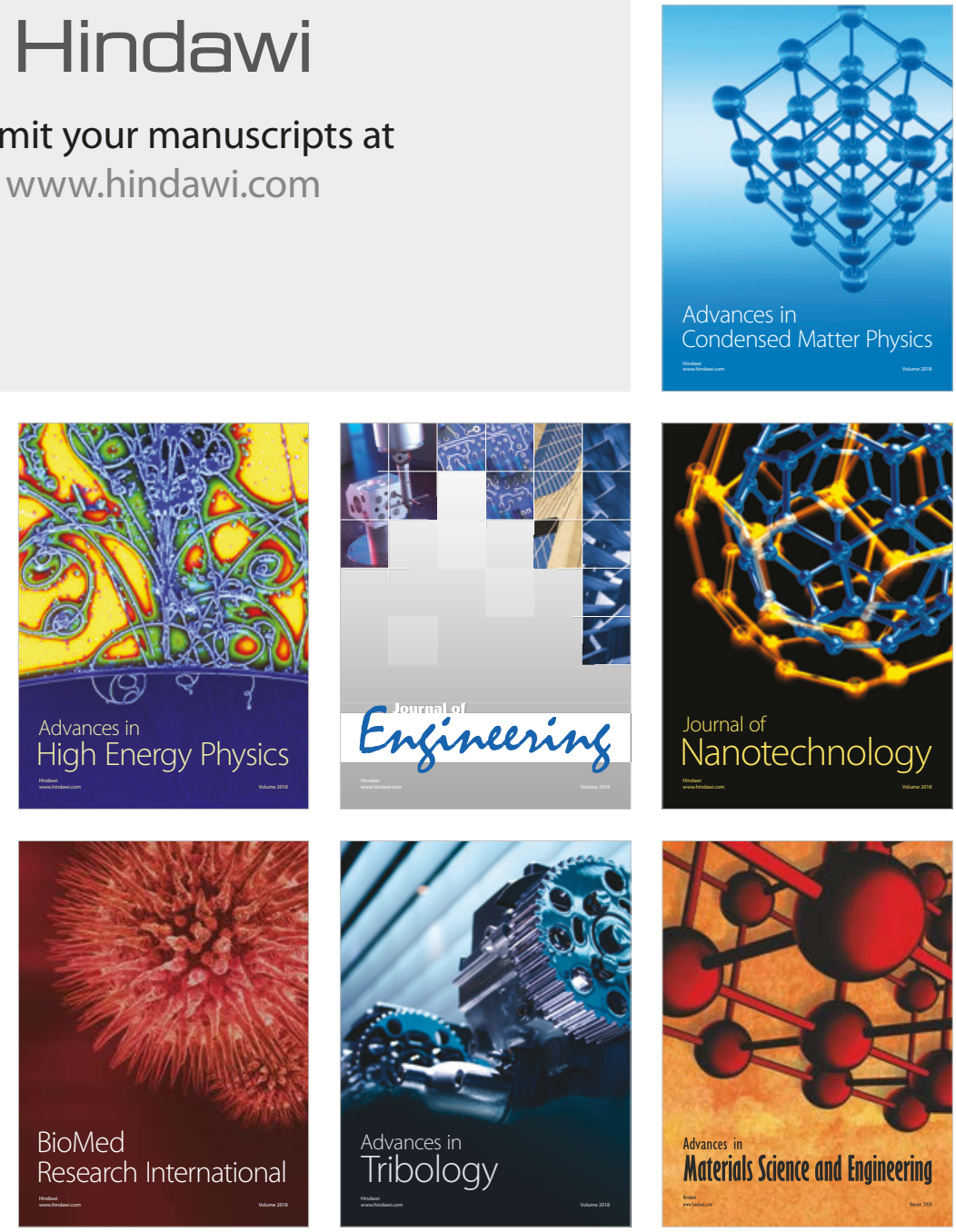